\title{
A tomada de consciência docente e discente sobre o desenvolvimento de habilidades para o desenho em perspectiva ${ }^{1}$
}

\author{
The grasp of consciousness of teachers and \\ students about the development of \\ perspective drawing abilities
}

${ }^{1}$ Versão expandida do artigo selecionado nos Anais do Graphica 2019

\author{
Adriane Borda Almeida da Silva \\ Doutora em Educação \\ Docente do Departamento de \\ Arquitetura e Urbanismo, \\ Universidade Federal de Pelotas, \\ Pelotas, Brasil \\ adribord@hotmail.com
}

Tássia Borges de Vasconselos

Mestre, Doutoranda no Instituto de Arquitetura e Urbanismo USP, São Carlos - SP, Brasil tassiav.arq@gmail.com

\section{Taís Feijó Viana}

Mestre em Arquitetura e Urbanismo - UFPel

Docente Curso Técnico em Edificações, Instituto Federal Sulrio-grandense, Pelotas - RS, Brasil taisfviana@gmail.com

\section{Tatiane Brisolara Nogueira}

Mestre em Arquitetura e Urbanismo - UFPel Docente Curso Técnico em Edificações, Instituto Federal Sulrio-grandense, Pelotas - RS, Brasil tatiane.b.nogueira@gmail.com

\section{Luciana Sandrini Rocha}

Mestre, Doutoranda em Informática na Educação - UFRGS Docente Curso Técnico em Edificações, Instituto Federal Sulrio-grandense, Pelotas - RS, Brasil luciana@pelotas.ifsul.edu.br

\section{RESUMO:}

A partir de inquietações docentes sobre as dificuldades de estudantes de arquitetura com o desenho em perspectiva ao longo do processo formativo, que compreende no mínimo cinco anos, imerge-se em teorias piagetianas na expectativa de melhor compreender tais dificuldades. Parte-se de uma análise comparativa de desenhos produzidos, em um contexto específico, nos momentos inicial e de conclusão de curso. Os desenhos analisados foram produzidos entre 2014 e 2019. Utiliza-se, especificamente, a teoria da equilibração das estruturas cognitivas e da abstração reflexionante, para pensar a construção de conhecimento sobre a lógica de sistemas projetivos. Este exercício tem permitido aguçar a percepção e identificar os elementos indicativos da tomada de consciência destas lógicas, por parte de cada estudante. Os resultados, sem o propósito de categorizar o perfil dos participantes, questionam o estabelecimento efetivo de um processo de abstração reflexionante junto à atividade de representar a mão livre, mesmo entre os concluintes. E, com isto, contribuem para a formação docente na área de representação, construindo critérios e apontando estratégias para a configuração de discursos didáticos que possam auxiliar, de maneira objetiva, os estudantes a aperfeiçoarem tal habilidade.

Palavras-chave: docência; representação gráfica; Piaget; abstração reflexionante; teoria da equilibração.

\begin{abstract}
:
Starting from teachers concerns about the difficulties of architecture students with drawing in perspective throughout the formative process, which comprises at least five years, immerses itself in Piagetian theories expecting a better understanding in such difficulties. It starts with a comparative analysis of drawings produced, in a specific context, at the initial and conclusion phases of the course. The analyzed drawings were produced between 2014 and 2019. The equilibration of cognitive structures and reflective abstraction theories are specifically used to think about the construction of knowledge about the logic of projective systems. This exercise has allowed to improve the perception and identification of the indicative elements of awareness of these logics by each student. The results, without the purpose of categorizing the profile of the participants, question the effective establishment of a process of reflective abstraction along with the activity of free hand representing, even among concluding students. Therefore, they contribute to the teacher education in the area of representation, building criteria and pointing out strategies for the configuration of didactic speeches that can objectively help students to improve this skill.
\end{abstract}

Keywords: teaching; graphic representation; Piaget, reflective abstraction; equilibration of cognitive structures. 


\section{INTRODUÇÃO}

Este estudo parte de reflexões sobre as trajetórias das próprias pesquisadoras, relativas as suas habilidades tanto para o desenho em perspectiva quanto para a docência neste tema específico. Todas elas com a mesma formação de graduação, em arquitetura, atuando como docentes em contextos diferentes e com tempos e tipos de investimentos formativos para tal também diversificados. As trajetórias incluem as experiências docentes tanto em cursos de graduação e pós-graduação quanto em nível técnico, variando de cinco a trinta anos de experiência. Tais reflexões buscam avançar na compreensão da eficácia do ensino formal de representação gráfica, particularizada, neste caso, pela produção de croquis em perspectiva junto a um contexto de formação em arquitetura.

Inicialmente, compreendemos que o desenho, no contexto de ensino de arquitetura, tem caráter representativo e de antecipação, confundindo-se muitas vezes com o próprio ato projetual. Investiga-se de que modo a formação acadêmica tem contribuído para a construção de conhecimentos em Geometria, que é a base teóricoconceitual da representação gráfica em arquitetura. De acordo com Gonçalves (2011):

\footnotetext{
O desenvolvimento da capacidade de fazer relações mentais por meio das noções de medidas, localização, posicionamento, rotação, deslocamento, escalas e representação, originados pela observação de elementos visuais, é promovido pelo estudo da Geometria, fazendo com que os estudantes ampliem a habilidade de compreender, previamente, o espaço e os objetos a serem criados (GONÇALVES, 2011, p. 99).
}

O desenho é a principal linguagem adotada como meio de comunicação em todas as fases de elaboração de um projeto, e é desenvolvido como um processo de codificação e decodificação de símbolos e signos próprios da representação gráfica. No âmbito de processos formativos de arquitetos, engenheiros e técnicos de especialidades que atuam sobre o espaço investe-se no reconhecimento de conhecimentos em geometria gráfica.

0 problema fundamental do desenho de arquitetura é como representar formas, construções e espaços tridimensionais em apenas duas dimensões. Três tipos distintos de sistemas evoluíram ao longo do tempo para cumprir essa missão: desenhos de vistas múltiplas, de linhas paralelas e em perspectivas cônicas. [...] Entender esses princípios e suas convenções é crucial para elaboração e leitura de desenhos de arquitetura (CHING, 2011, p. 35).

Estes sistemas, referidos por Ching, estão fundamentados no âmbito das geometrias clássicas (Quadro 1). Cada tipo de desenho adquire uma estrutura em função dos tipos de transformações geométricas aplicadas aos elementos das figuras representadas. Estas transformações podem ser por isometrias, semelhanças, afinidades ou projetividades (Sanz; Moratalla, 1998). Esta sequência, que traduz uma lógica de aumento de complexidade, da geometria euclidiana à projetiva, é inversa à quantidade de invariantes projetivos envolvida em cada uma. Observa-se que à Geometria Projetiva, que fundamenta todo o desenho em perspectiva, está associado um único invariante projetivo: manutenção das razões duplas. Os programas curriculares são tradicionalmente organizados buscando traduzir esta sequência, exatamente porque o aumento de complexidade exige uma capacidade maior de abstração. Partem do estudo geométrico das figuras planas até as espaciais, das transformações isométricas (de manutenção de medidas e ângulos, e consequentemente de paralelismos e razões duplas) até as projetivas. Para além destas geometrias clássicas, se avançaria para níveis mais altos de 
abstração, para incluir, por exemplo, estudos no campo da topologia. Neste caso, são permitidas transformações a partir, por exemplo, de torções e aplastamentos, modificando assim de maneira mais radical todas as relações entre os elementos, mas mantendo noções de lugar, como dentro, fora, direita, esquerda, etc. E, ainda se poderia considerar níveis mais altos de abstração, como por exemplo, a geometria fractal, indo muito além do escopo deste estudo.

Quadro 1: Geometrias clássicas e Topologia.

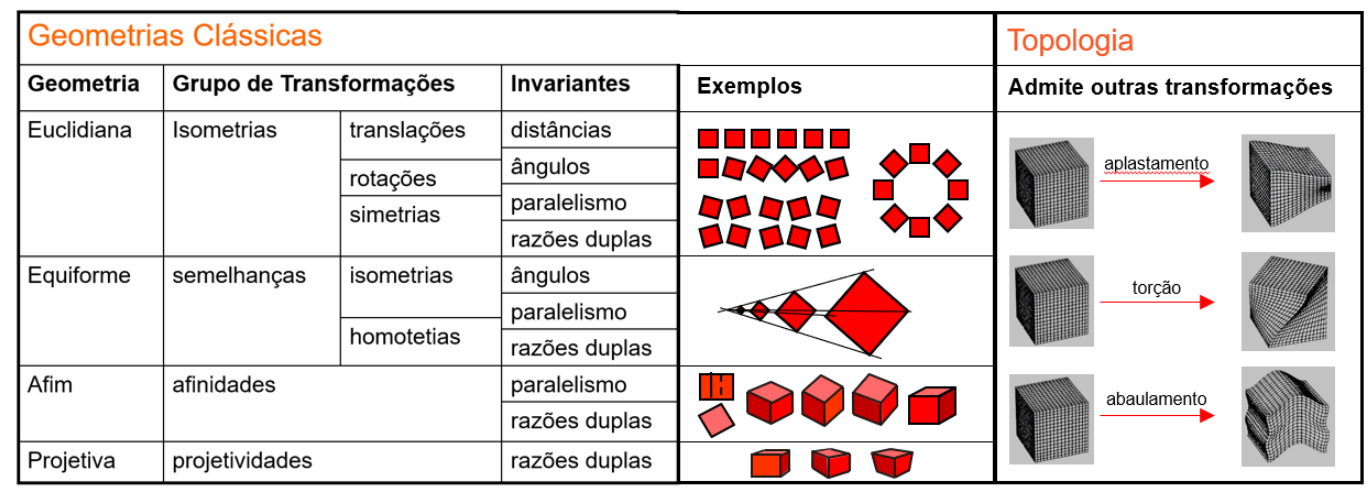

Fonte: Adequado de Sanz e Moratalla (1998) e ampliado (autoras).

Junto à formação em arquitetura, os estudos básicos de geometria plana e espacial são considerados relativos ao ensino fundamental e médio, abordando-se diretamente os estudos de projeção paralela ortogonal (geometria descritiva e projeção cotada), para logo abordar o desenho em perspectiva, adicionando-se então as projeções oblíqua e cônica. Desta maneira, exige-se do estudante ingressante uma capacidade de abstração capaz de compreender os procedimentos projetivos, para, então, representar o espaço tridimensional em um espaço bidimensional, no plano da imagem. Entretanto, o desenvolvimento desta capacidade de abstração tem tido pouco investimento junto ao sistema educativo prévio à graduação. Esta percepção, adquirida não somente pelas experiências discentes e docentes aqui envolvidas, é também estudada e confirmada por diversos autores no Brasil (KOPKE, 1996; 2009 e BUENO, 2015). Frente a isto, por parte dos discursos didáticos, faz-se necessário, frequentemente, investir no resgate, ou mesmo na construção de conceitos básicos de geometria, para logo poder abordar o desenho em perspectiva.

No contexto do presente estudo, o conjunto de representações da Figura 1 é apresentado na introdução de uma disciplina de primeiro semestre, logo após coletar dados sobre os conhecimentos prévios dos ingressantes quanto a esta habilidade específica. Para isto, são solicitados a representar cubos em perspectiva, utilizando-se do desenho à mão livre, e logo são provocados a identificar os tipos de sistemas utilizados, comparando com aqueles apresentados na Figura 1. A provocação tem o propósito específico de tratar de construir um olhar analítico para a compreensão dos invariantes projetivos associados a cada representação, referidos no Quadro 1. Para cada estrutura, objetivamente, faz-se o seguinte questionamento: que tipo de transformação ocorre em termos de distâncias, ângulos e paralelismos?

Figura 1: Representações de um cubo. Na sequência: sistema paralelo ortogonal (1 projeção, bi-projetivo, iso, di e trimetria); paralelo oblíquo; sistema cônico (1, 2 e 3 pontos de fuga). 


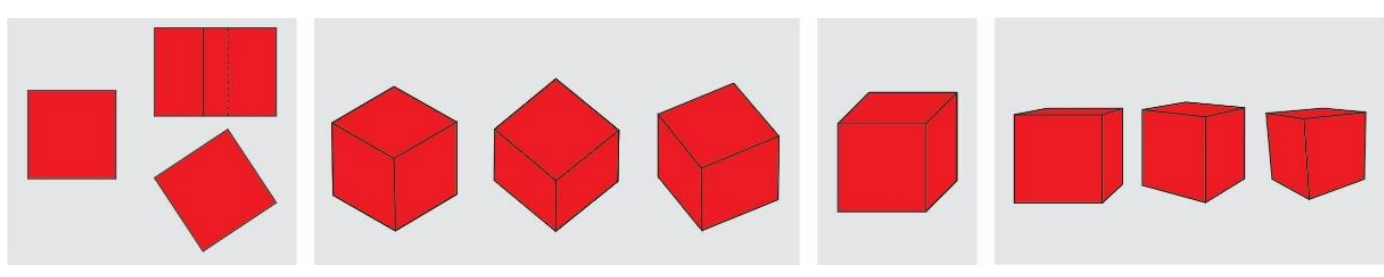

Fonte: Autoras.

A compreensão destas lógicas fica perfeitamente evidenciada na prática de representação em croquis de arquitetura, percebe-se quando existe o controle efetivo das estruturas correspondentes à cada sistema. A desestruturação ou inconsistência na representação, que dificulta a comunicação, atribui um diferencial muito frequente entre os estudantes, promovendo, mesmo entre eles, a etiquetagem naqueles "talentosos" para o desenho. E, muitas vezes, esta diferenciação induz, por consequência, a falta de motivação para investir no desenvolvimento de tais habilidades a partir de um conhecimento construído neste momento formativo.

Entretanto, a síntese, traduzida pelo Quadro 1, ou pelo conjunto de imagens da Figura 1, deve ser compreendida frente ao tempo histórico em que foi construída, atentando para a complexidade do tipo de conhecimento envolvido.

\subsection{A dimensão genética dos procedimentos projetivos (constituição histórica dos}

\section{saberes do campo da geometria)}

Compreender a dimensão genética deste conhecimento tem auxiliado a ação docente e talvez venha sendo pouco enfatizada junto à ação discente. A tomada de consciência de tal complexidade auxilia a compreender as dificuldades para 0 desenvolvimento das habilidades para o desenho em perspectiva. A partir de Borda (2001), tem-se um estudo sobre o processo histórico de constituição dos saberes da Modelagem Geométrica. Estes saberes, próprios da Informática Gráfica, observados sob a perspectiva deste estudo, oportunizaram a automatização dos procedimentos projetivos, atribuindo até mesmo um caráter lúdico, sem envolver processos cognitivos complexos. Representar um cubo sob qualquer ponto de vista tornou-se uma tarefa muito simples e intuitiva com a interface de ferramentas gráficas no espaço digital. Para tanto, este processo histórico envolveu níveis bem mais elevados de abstração, frente à necessidade de traduzir o desenho à linguagem binária dos computadores. Com isto, a história do desenho projetivo forneceu elementos fundamentais para tal evolução.

De acordo com a leitura realizada em Borda (2001), compreende-se, a partir do estado da arte, que a automatização dos procedimentos projetivos implícitos à Modelagem Geométrica foi sendo estruturada na medida em que as linguagens gráficas foram sendo correspondidas às algébricas, e vice-versa, estabelecendo-se assim a linguagem gráfico-algébrica. A gráfica, foi sendo constituída no âmbito dos postulados de Euclides (300 a.C.), à sistematização da Perspectiva no século XV, ou também à Geometria Descritiva, já no final do século XVIII. A trajetória de estruturação da linguagem algébrica, inclui saberes desde a Aritmética até a Álgebra, evoluindo para a Geometria Analítica e a Diferencial. Uma linguagem foi continuamente potencializada pela outra, tendo-se o caso emblemático das fortes interações provocadas por Gaspar Monge entre a sistematização, em paralelo no tempo, da Geometria Diferencial e da Descritiva. Em crescente 
complexidade destas interações, é somente na primeira metade do século XIX que ocorre a sistematização da Geometria Projetiva, havendo assim a tradução do desenho ao número, por meio da linguagem gráfico-algébrica.

Os princípios lógicos dessa tradução já estavam estabelecidos desde muito tempo por meio de experimentos com as superfícies cônicas, para depois vir a constituir o conceito de invariante projetivo. Surgiu então, a partir da compreensão das relações estabelecidas entre as seções planas (circunferência, elipse, parábola e hipérbole) decorrentes de estarem conectadas por um feixe de retas que parte de um mesmo ponto (vértice da superfície cônica). Neste sistema, encontram-se as ações fundamentais de um sistema projetivo: projetar e cortar. Assim como, pode-se abstrair para a caracterização dos próprios elementos constituintes deste sistema: vértice, como observador; feixe de retas, como projetantes; seções como projeção (figuras planas/imagens), produzidas pelo plano de seção. Este, por sua vez, como plano de projeção (plano do quadro). Sendo que as posições relativas entre estes elementos caracterizam diferentes sistemas com estruturas próprias, regidas então pelos invariantes projetivos. Ao abstrair a localização do observador no infinito, tem-se a caracterização do sistema cilíndrico ou paralelo de projeção. Entretanto, para a algebrização de todas estas relações custou para a ciência um tempo de mais de 500 anos. E, seguindo esta leitura histórica, observa-se que a topologia, com suas lógicas muito primárias em termos intuitivos (dentro e fora, direita e esquerda, ...) foi modelada no sentido matemático somente no final do século XIX. Igualmente aos demais que a precederam, resultou da reorganização de um conjunto de saberes, potencializados entre si, havendo complexidade crescente para obter modelos representativos de transformações geométricas. Nesta trajetória, desde o espaço euclidiano ao topológico, compreende mais de dois mil anos para tecer esta rede de saberes.

A observação da constituição de um conhecimento no tempo, além de evidenciar a elevada abstração necessária para seu entendimento, instiga a aproximação às teorias piagetianas. Os estudos do biólogo e epistemólogo suíço Jean Piaget, partiram do propósito de entender os processos de construção do conhecimento em si, delimitando o campo da epistemologia genética (PIAGET, 2007). Entretanto, estes estudos acabaram levando Piaget a observar diretamente a psicogenética do desenvolvimento da criança, a partir das noções do espaço. Com isto, buscou compreender como desenvolvemos a capacidade de abstração para poder avançar de conhecimentos mais simples para os mais complexos. Neste tema estabeleceu uma parceria de mais de 40 anos com a psicóloga suíça Bärbel Inhelder, investigando a "compreensão do espaço e da geometria pela criança" (KESSERLING, 2008 p. 43). Por envolverem assim, a construção de um conhecimento em geometria, tais teorias são aqui estudadas.

Apesar do foco, no caso do presente estudo, ser a aprendizagem de jovens ou adultos ingressantes em um curso de arquitetura, entende-se fundamental a compreensão da gênese do processo cognitivo relativo ao raciocínio visuoespacial. Outros autores, como Rodrigues (1996), Silva Jr. (2007), Moniz (2013) e Pereira, Duarte e Lopes (2011) também se apropriaram das teorias de Piaget para estudar os processos cognitivos envolvidos no ato de desenhar dirigidos a um grupo de jovens/adultos.

\subsection{Desenvolvimento de estruturas cognitivas para a compreensão do espaço e da}

\section{geometria}


Segundo Piaget, a criança nasce com a capacidade de desenvolver estruturas cognitivas, e não propriamente com estas estruturas. Esta capacidade passa a ser desenvolvida em função de sua interação com o meio, como uma necessidade humana, latente. A partir de suas observações ele identificou estádios de desenvolvimento destas estruturas que evoluem, em geral, conforme a idade: o sensório-motor (dos 0 aos 2 anos), quando se dá o início das interações sociais e a criança assimila e estuda objetos e suas propriedades a partir dos esquemas de ação que dispõe; o pré-operatório (entre 2 e 7 anos), quando se inicia a atividade representativa resultante da interiorização das ações motoras decorrentes do desenvolvimento anterior; o operatório concreto (entre 7 e 12 anos), quando a atividade representativa é mais desenvolvida, a criança pode imaginar transformações e consegue realizar operações lógicas matemáticas elementares, mas depende ainda do apoio do concreto; o das operações formais (a partir dos 11-12 anos), quando é evidenciada a capacidade de reversibilidade de operações podendo, assim, operar tanto do concreto ao abstrato quanto do abstrato ao concreto, tendo a consciência de que se trata de uma mesma operação. Entretanto, esta cronologia é variável de acordo com as condições individuais de cada sujeito, bem como o tipo de estímulo recebido em seu meio social.

Por razões metodológicas, Piaget e Inhelder trabalharam em suas pesquisas com sujeitos de idade máxima de 16 e 17 anos, em função de que "a capacidade cognitiva do adulto depende, mais intensamente do que a da criança, das suas condições de socialização" (KESSERLING, 2008 p. 149). Contudo, deve-se compreender que cada um desses períodos se caracteriza pela conquista, pelo indivíduo, de competências que avançam gradualmente desde as operações mais simples com objetos concretos até os mais elevados níveis de abstração, que constituem o desenvolvimento do raciocínio lógico-matemático e onde o indivíduo torna-se capaz de operar exclusivamente com hipóteses. Assim, entende-se que

Os esquemas de comportamento e pensamento dos níveis inferiores são, por conseguinte, integrados pelos níveis superiores e ajustados a esses. Isso significa, no entanto, que as capacidades adquiridas nos níveis precedentes não se perdem nos subsequentes, mas são mantidas (embora sob forma alterada) (KESSERLING, 2008, p. 101).

A teoria da equilibração das estruturas cognitivas de Piaget (1976) explica que cada estádio é caracterizado por processos graduais de assimilação, acomodação e equilibração, necessários ao desenvolvimento do estádio seguinte. Esses processos ocorrem de modo cíclico e quase simultaneamente, ou seja, a cada assimilação - que ocorre em função de um novo estímulo ou desequilibração - corresponde uma nova acomodação e um novo patamar de equilibração, que prepara para a próxima assimilação, e assim por diante, o que caracteriza nossa capacidade de construir conhecimentos ao longo da vida. Para Kesserling (2008),

Fundamentalmente, Piaget considerou a equilibração como o processo pelo qual se efetiva a construção das estruturas do conhecimento. Quando, no entanto, ele se dedicou ao exame detalhado desse processo, notadamente em vastos segmentos de sua obra empírica, ele não deixou dúvida de que a equilibração consiste numa multiplicidade de processos concorrentes. Dos mais importantes fazem parte a assimilação e a acomodação, a abstração reflexionante (abstraction réflechissante), a tomada de consciência (prise de conscience) e a descentração (décentration)" (KESSERLING, 2008, p. 80). 
Piaget e Inhelder (1993), apoiando-se em uma linguagem geométrica de significado correspondente com aquele tratado na abordagem histórica, porém em relação ao momento de construção da ideia e não propriamente em seu momento de algebrização, afirmam que o espaço perceptivo

\footnotetext{
é construído segundo uma ordem de sucessão que vai de relações topológicas iniciais a relações projetivas e métricas, depois, finalmente, a relações de conjuntos ligadas aos deslocamentos dos objetos, uns relativamente aos outros (PIAGET; INHELDER, 1993, p. 60).
}

Os autores observam que a criança se relaciona ativamente, desde cedo, com o espaço sensório-motor, através da percepção e do desenvolvimento da motricidade, avançando até a conquista da linguagem e da representação figurada. Destacam a diferença entre o espaço perceptivo (ou sensório-motor) e o espaço representativo (ou intelectual), explicando que "a percepção é constituída em contato direto com o objeto, ao passo que a imagem intervém em sua ausência" (PIAGET; INHELDER, 1993). Segundo eles,

É a partir do momento em que aparece a função simbólica, isto é, em que se diferenciam os "significantes", sob a forma de símbolos (imagens) ou de signos (palavras), e os "significados", sob a forma de relações pré-conceituais ou conceituais, que a representação é acrescentada à atividade sensório-motriz. É nesse nível que começa o espaço representativo [...] (PIAGET; INHELDER, 1993, p. 472).

Compreende-se que a representação surge por meio da ação interiorizada sobre o espaço. "Por mais indispensável que seja a título de suporte ou significante, não é a imagem que determina as significações: é a ação assimiladora que constrói as relações, cuja imagem não é senão um símbolo" (PIAGET; INHELDER, 1993, p. 476). Assim, quando a imagem é produzida sem estas relações, apresenta caráter puramente figurativo, sem significado. Por exemplo, no caso de um cubo pelo sistema paralelo oblíquo, o protocolo frequentemente ensinado desde o fundamental consiste no deslocamento de um quadrado em relação ao outro e, logo, à conexão entre os vértices (à esquerda da Figura 2). A partir da experiência docente, identifica-se recorrentemente tratar-se muito mais da memorização de uma imagem do que de uma representação propriamente dita, ou seja, a ação assimiladora das relações envolvidas no sistema projetivo adotado. Esta lógica repete-se com o protocolo de representação de um cubo em isometria, ilustrado à direita da Figura 2. É bastante frequente os estudantes de arquitetura terem dificuldades de compreender, por exemplo, que as arestas de altura também estão igualmente inclinadas em relação ao plano de projeção. Comum também haver um traço involuntário, junto a uma representação própria de um sistema paralelo, apontando para a configuração de pontos de fuga. Poderíamos interpretar como uma dificuldade se colocar no lugar do outro, ou mais precisamente, de se colocar em um local abstrato como se caracteriza um ponto de vista situado em um ponto impróprio? E, estando ali situado, o estudante entende que utiliza um feixe de retas paralelas para executar a projeção? Existe esta tomada de consciência sobre tais relações e consequências em termos de representação? Os discursos docentes cansam de repetir: "tudo que está paralelo no espaço, em um sistema paralelo, segue paralelo em projeção". 0 quanto este invariante projetivo (paralelismo) é efetivamente compreendido? Ou apenas as representações paralelas são construídas como imagem?

Figura 2: Protocolos gráficos de representações de um cubo em perspectiva paralela oblíqua e ortogonal, no caso, em isometria. 


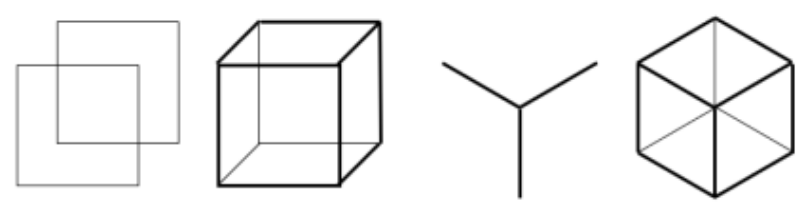

Fonte: Autoras.

Para este tipo de problematização, em Piaget (1995) encontra-se o conceito de abstração reflexionante. Para apresentar este conceito, o autor argumenta que, enquanto a abstração empírica diz respeito a tudo que pode ser observável, ou seja, ao conhecimento sensorial, a abstração reflexionante se caracteriza pela retirada de qualidades dos objetos, através de processos endógenos de coordenações das ações que são associados ao raciocínio lógico-matemático. No caso, pode-se extrair a qualidade de manutenção de paralelismos entre arestas de mesma direção, como já mencionado, para o caso das perspectivas paralelas. Piaget considera que é no ápice do processo da abstração reflexionante que ocorre a tomada de consciência pelo sujeito. A partir do estabelecimento de um processo de abstração reflexionante, o estudante, ao representar, por exemplo, a perspectiva da esquerda da Figura 2, estaria ciente de que trata-se de um sistema abstrato, que não tem a ver com o que seria produzido por uma fotografia, pois, neste caso, haveria um ponto de vista determinado. Estaria ciente dos componentes de todo o sistema projetivo e das posições relativas entre eles. Ciente também da necessidade de normatizar as razões entre ângulo de fugitivas e fator de redução das profundidades, para que se assemelhe ao sistema perceptivo e se reconheça então como um cubo e não um poliedro reto qualquer. Estaria ciente de todas as elaborações no tempo para a sistematização do conhecimento que está tratando.

Kesserling (2008) facilita a compreensão do conceito de abstração reflexionante, exemplificando o isolamento de uma qualidade perceptível de uma folha, remetendo a sua tonalidade verde e à evolução para o conceito de cor. Transpondo a explicação, quando abstraímos a qualidade perceptível de um desenho em perspectiva, como qualquer um dos apresentados na Figura 2, isolamos aspectos individuais para logo avançar ao conceito de invariantes projetivos e generalizar, para os casos em questão, a manutenção dos paralelismos e das razões duplas.

Isolar e generalizar compõem, portanto, ambos os passos daquela abstração que leva à formação de conceitos empíricos. Dessa abstração comum ou (como também a chamava) empírica, Piaget distinguiu a chamada abstração reflexionante (réflechissante). Ela também conduz a conceitos, partindo, no entanto, de aspectos ou de propriedades de ações ou operações - quiçá de regras de ação e operação ou de prescrição, de modos de agir, de pontos e vista que influem no estabelecimento de relações, etc. A maior parte dos conceitos lógicos e matemáticos são devidos a tais abstrações reflexionantes. Uma abstração empírica leva a uma constatação; a abstração reflexionante atinge maior profundidade e leva à compreensão (KESSERLING, 2008, p. 86).

Nos estádios sensório-motor e pré-operatório, bem como em parte do operatório concreto, a representação espacial tende a ser apenas uma "evocação figurada", uma reprodução de imagens conhecidas, e a criança ainda não é capaz de operar com os objetos ativamente (representar, por exemplo, um objeto em diferentes pontos de vista ou imaginar a seção de um objeto qualquer sem precisar executá-la). A representação espacial passa a ser uma ação interiorizada quando ela adquire domínio sobre significantes e significados, e já não depende de objetos concretos para operar com eles, 
dominando a habilidade de reversibilidade. Esta habilidade, ou seja, a capacidade de trabalhar sobre hipóteses, é desenvolvida, em geral, ao longo do estádio operatório concreto. Assim,

[...] a intuição do espaço não é mais uma leitura das propriedades dos objetos, mas, antes, desde o início, uma ação exercida sobre eles; e é porque essa ação enriquece a realidade física, ao invés de extrair dela, sem mais, estruturas completamente formadas, que ela consegue ultrapassá-la gradualmente, até constituir esquemas operatórios suscetíveis de serem formalizados e de funcionarem dedutivamente por si mesmos (PIAGET; INHELDER, 1993, p. 469).

0 diálogo estabelecido por Piaget com a geometria facilita compreender que as noções do espaço são construídas em função do desenvolvimento de relações de caráter topológico, projetivo e euclidiano. Ele explica que, enquanto as relações de caráter topológico dizem respeito às operações infralógicas, as de caráter projetivo e euclidiano estão relacionadas às operações lógico-aritméticas, caracterizadas pela abstração reflexionante. As relações topológicas se estabelecem a partir da intuição espacial que ocorre no início da percepção ativa e do desenvolvimento da motricidade. Nesta concepção, as relações espaciais elementares são: 1) de vizinhança ou proximidade entre elementos que se encontram num mesmo campo de visão; 2) de separação ou dissociação, distinguindo elementos entre si numa determinada totalidade; 3 ) de ordem ou sucessão espacial, entre elementos ao mesmo tempo vizinhos e separados e organizados de modo sequencial ou de repetição, como as simetrias; 4) de circunscrição ou envoltório, como ocorre na relação de interioridade de um objeto dentro de uma caixa; e 5) de continuidade de linhas e superfícies, relacionada à percepção de um campo espacial contínuo. $\mathrm{Na}$ geometria estas relações constituem a topologia, que diz respeito às relações elementares de uma mesma figura considerada em si mesma e da analogia entre uma figura e outra, distinguindo-se das noções de formas rígidas, de distâncias, retas, ângulos, medidas e relações projetivas (PIAGET \& INHELDER, 1993). Aqui é importante perceber a diferença dos níveis de complexidade referida anteriormente, junto à história da sistematização da topologia. Neste caso, refere-se às ideias intuitivas em relação ao espaço e não sobre a elaboração matemática para a implementação de algoritmos capazes de traduzir as relações topológicas (por exemplo, para ensinar a uma máquina o que está dentro ou fora de um objeto).

As relações projetivas, no campo da intuição sobre o espaço, evoluem, por sua vez, a partir das relações topológicas (homeomorfias, ou intrínsecas ao objeto), mas diferenciam-se destas por se tratarem de relações entre objetos de um sistema. Em uma representação projetiva, o objeto ou sua figura passa a ser considerado a partir de um ponto de vista e das relações que estabelece neste conjunto.

Com as noções projetivas, as formas das figuras, suas posições respectivas e as distâncias aparentes que as separam, mas todas sempre relativamente a um ponto de vista considerado, são acrescentadas às relações topológicas internas" (PIAGET; INHELDER, 1993, p. 488).

Estas noções referem-se tanto aos pontos de vista coordenados quanto aos planos sobre os quais se projetam as figuras. "Nas relações projetivas, nem as paralelas, nem os ângulos, nem as distâncias são ainda conservadas" (PIAGET; INHELDER, 1993, p. 495).

Assim como as relações projetivas, as relações euclidianas também derivam das relações topológicas. Ambas constituem relações de desenvolvimento mais tardio, e ainda 
que sejam independentes entre si, são solidárias. As relações euclidianas baseiam-se na conservação de distâncias, paralelismos ou convergências, proporções e ângulos.

Piaget defende que o raciocínio lógico-matemático é construído a partir da experiência ativa sobre o espaço sensório-motor. Ele se apropria do conhecimento matemático para explicar, do ponto-de-vista da Psicologia, como ocorre a genética do desenvolvimento cognitivo espacial em crianças. No entanto, Piaget observa uma ordem de aquisição de habilidades por parte dos indivíduos (inicialmente as relações topológicas, e a partir destas as relações projetivas e euclidianas) distinta da evolução da Matemática como ciência:

[...] essa ordem de sucessão nada tem de necessária e encontra-se mesmo tão pouco com as ideias habituais sobre a representação espacial que, a nosso ver, ela ainda não foi reconhecida [...]. Tal inversão da ordem genética perceptiva não teria tido nada de absurdo, pois a ciência geométrica seguiu esse caminho: os elementos de Euclides apoiam-se na geometria métrica e nas semelhanças, a geometria projetiva só tomou corpo nos séculos XVII (Desargues), XVIII (Monge) e XIX (Poncelet), ao passo que a Analisis situs ou topologia é uma concepção moderna. Poderia, pois, ter acontecido de a representação intuitiva, como a análise reflexiva, ter invertido a ordem da gênese real e é o que se admite geralmente quando a ordem reflexiva e a ordem genética não são confundidas, ao modo dos autores de tratados elementares que partem da distância e das figuras euclidianas simples como se se tratasse dos "elementos" reais da construção do espaço (PIAGET; INHELDER, 1993, p. 61).

Trazendo-se estas duas leituras, da abordagem da construção do conhecimento na história e da abordagem psicogenética, reúnem-se elementos que potencializam a reflexão: por vezes parecem indicar crescimentos em sentidos contrários, quanto aos níveis de abstração associados a cada tipo de conhecimento, do espaço topológico, projetivo e euclidiano. Mas, ao tratar do tipo de abstração envolvida, empírica ou reflexionante, compreende-se a correspondência entre tais leituras.

\subsection{A construção do conhecimento discente}

No caso aqui abordado, de desenho projetivo, talvez se possa associar o estabelecimento de uma abstração empírica junto ao processo de representações digitais produzidas pelos estudantes de maneira automatizada. Este tipo de experiência facilita a construção de um conhecimento sensorial, de relações topológicas, mas pode não necessariamente levar a uma abstração reflexionante. Esta sim, como foi visto, exige o estabelecimento de processos endógenos de coordenações das ações que são associados ao raciocínio lógico-matemático. A representação digital pode estar envolvendo somente uma representação figurativa, de observação da imagem. Entende-se ser mais fácil de perceber a instalação de uma abstração reflexionante a partir de um desenho a mão. Para este tipo de desenho faz-se necessário de ante mão decidir o sistema de representação a ser adotado e logo, compreender as estruturas e seus invariantes projetivos. Entretanto, em qualquer caso, dependerá da tomada de consciência sobre o conhecimento envolvido.

Interpretar os desenhos produzidos pelos estudantes a partir dessa compreensão pode auxiliar os docentes sobre quais conhecimentos devem ser explicitados para que haja avanço na aprendizagem e, a partir disso, propor estímulos capazes de desencadear processos de construção de conhecimento que levem à tomada de consciência por parte dos mesmos, em relação ao(s) sistema(s) de projeção utilizado(s). Para tal, o estímulo 
deve ser capaz de desequilibrar (no sentido piagetiano) as estruturas existentes, caracterizando um processo de assimilação, que por sua vez gera uma nova acomodação e um novo patamar de equilibração.

Os estudos até aqui mencionados, permitiram destacar a dúvida, pela experiência docente das autoras envolvidas nesta reflexão, sobre a possível permanência da produção, por alguns indivíduos, de representações figurativas mesmo ao final de um processo formativo em arquitetura. Com base na obra de Piaget, Kesserling (2008) observa que

Quem sabe como algo se faz sabe, também, de modo geral, quando incorre em algum erro. A tal saber intrínseco à ação (...), segue-se a capacidade de revelar as regras ou os esquemas utilizados, o que se manifesta, não raro, apenas anos depois. É essa capacidade que pressupõe uma abstração reflexionante (KESSERLING, 2008 p.86).

Assim, o presente estudo se propõe a refletir sobre a problemática relativa ao desenvolvimento de estruturas cognitivas necessárias à construção de conhecimentos em geometria, caracterizados pelo processo de abstração reflexionante, bem como ao pouco tempo dedicado ao processo formativo nessa área, tanto docente quanto discente.

\section{METODOLOGIA}

De acordo com o exposto na introdução, este estudo partiu do interesse formativo de um grupo docente a fim de compreender as dificuldades dos estudantes de arquitetura para o desenho em perspectiva. Como método, buscou-se inicialmente entender a dimensão genética do conhecimento tratado, e, logo, compreender como se dá o desenvolvimento cognitivo para a apropriação do mesmo. Estabelecendo-se um processo dialógico entre estas duas abordagens, a histórica e a piagetiana, os desenhos referidos passaram a ser analisados pelo grupo, utilizando-se de critérios apoiados na explicitação de elementos que identifiquem a compreensão do conceito de invariantes projetivos. Sendo assim, partiu-se da consideração de que estes elementos podem apontar para a tomada de consciência, ou não, sobre a lógica dos sistemas projetivos adotados em cada representação.

Os desenhos em perspectiva e produzidos à mão livre (representações gráficas de um cubo) decorrem de um processo de coleta em duas etapas, relativas aos momentos de ingresso e de conclusão de curso, obtendo-se assim representações realizadas pelo mesmo sujeito. 0 acervo de desenhos vem sendo constituído desde 2001, com certa continuidade em relação à coleta da primeira etapa. Entretanto, com muitas descontinuidades em relação à segunda. As reflexões aqui registradas, as quais não tem o propósito de análises quantitativas e nem tão pouco comparativas entre as habilidades dos estudantes, são relativas aos desenhos produzidos no período de 2014 a 2019. Contou-se, neste intervalo de tempo, com 25 casos passíveis de análise: desenhos de início e final de curso do mesmo estudante.

A coleta da primeira etapa, junto à aula inaugural da disciplina de primeiro semestre, é realizada utilizando-se de um exercício com o seguinte enunciado: representar um cubo, uma esfera e uma árvore, cada um deles sob três pontos de vista diferentes, em perspectiva (de acordo com a compreensão de cada um sobre este conceito). Este exercício é proposto para ser realizado em apenas dez minutos, partindose do pressuposto que, com este tempo, as representações serão realizadas a partir de um 
repertório mais imediato possível. Fica explícito o caráter não avaliativo e sim de registro do conhecimento prévio, individual, e o propósito de facilitar a autoavaliação, por cada estudante, junto ao momento de conclusão da disciplina. Os desenhos para a segunda etapa de coleta são realizados entre os dois últimos semestres de curso, partindo-se do mesmo tipo de enunciado, recontextualizando o discurso e explicando os interesses da pesquisa, solicitando que voluntariamente participem, com a garantia do anonimato da autoria de qualquer um dos desenhos. A Figura 3 exemplifica o tipo de resultado do exercício: no máximo nove representações, tendo em vista que nem todos os estudantes ingressantes, ou até mesmo concluintes, atendem ao enunciado completamente. Muitos justificam que o tempo dado é exíguo. Destaca-se também, junto ao enunciado, em ambas as etapas, sobre a recomendação de não utilizar borracha, sendo importante que todas as tentativas de redirecionamento do traço constituam a história do desenho, aconselhandoos a reforçar, caso necessário, os traços considerados mais representativos.

Figura 3: Desenho elaborado por uma estudante ingressante.
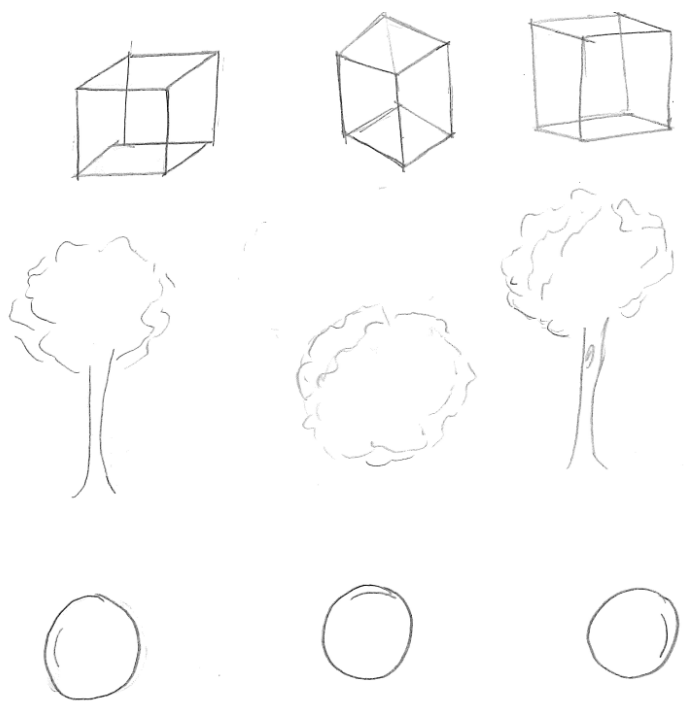

Fonte: Autoras.

Após a finalização do exercício, busca-se empoderar os estudantes com a percepção de que quem sabe desenhar um cubo em perspectiva, deveria saber desenhar qualquer coisa, desde que compreenda as possíveis relações geométricas entre a forma desta coisa com este cubo (ou com um poliedro reto qualquer, dependendo das proporções entre altura, largura e profundidade). Isto é muito enfatizado, visto que todos os estudantes, mesmo em um momento inicial, conseguem aproximar-se da tarefa de comunicar, por meio da perspectiva, a forma de, pelo menos, um cubo. Para validar este discurso de empoderamento, introduz-se diretamente o conceito de sólido envolvente como método de representação, largamente difundido por Montenegro (1983). Tanto para o caso da esfera quanto para o da árvore, destaca-se a lógica de identificação destas relações e das razões entre altura, largura e profundidade intrínsecas a estes objetos, facilitando a estruturação do desenho.

Deve-se destacar que as reflexões iniciais relativas a este estudo foram apresentadas junto ao Graphica 2019, fórum científico promovido pela Associação Brasileira de Expressão Gráfica (ABEG). Buscou-se com este trabalho, explicitar com mais 
detalhes, os referenciais teóricos adotados. Este detalhamento retoma a discussão no grupo e provoca a revisão dos materiais e métodos a serem utilizados para compreender como os desenhos coletados podem fornecer elementos que elucidem as questões didáticas aqui formuladas. Desta maneira, as análises ainda abarcam especificamente as representações do cubo, como um Estudo Piloto. Desde o seu início, o estudo contou com as seguintes etapas: A. Revisão bibliográfica, centrada especificamente no estudo da teoria piagetiana associada ao estudo da geometria; B. Coleta dos dados e estruturação do método de Análise (Estudo de caso); C. Análise dos dados (Estudo Piloto) e D. Discussão.

\section{DESENVOLVIMENTO}

\subsection{A estruturação do método de análise}

0 método de análise foi estruturado com o propósito de identificar a compreensão dos invariantes projetivos a partir de cada um dos sistemas adotados para a representação do cubo (uma abordagem projetiva e euclidiana). Desta maneira, analisam-se as habilidades no espaço representativo (intelectual ou lógico-matemático), para além do perceptivo (sensório-motor). Busca-se assim identificar elementos que indiquem a tomada de consciência de cada estudante em relação ao sistema adotado, tendo-se em vista a dúvida de que muitos estudantes ingressam, e mais do que isto, concluem o curso com a reprodução de imagens (evocação figurada) e não propriamente executando a operação da representação, com a tomada de consciência da lógica das transformações no espaço projetivo, características do processo de abstração reflexionante.

Na primeira linha (objeto de análise) tem-se os desenhos separados em colunas, sendo nas três primeiras os do momento de ingresso e nas outras três os de conclusão. Na segunda linha (análise da estrutura), sobre os mesmos desenhos, utiliza-se da cor para evidenciar as relações entre arestas de mesma dimensão: largura, em laranja; altura, em preto; profundidade em azul. Em vermelho estão representadas as direções relativas aos sistemas considerados mais próximos às direções dos desenhos: direção das fugitivas, quando próximo ao sistema paralelo oblíquo; direções que definem um triedro em isometria; direções que indicam pontos de fuga, no caso de estruturas indicativas da adoção de um sistema cônico. Os círculos em cinza estão posicionados nos vértices dos triedros considerados para selecionar as arestas a serem comparadas em suas dimensões. Na terceira linha, (análise de proporção), registra-se a justaposição das arestas do triedro referido, analisando-se as proporções entre elas, para concluir sobre a coerência com as lógicas dos sistemas adotados. Em vermelho, está a representação de um quadrado de acordo com o sistema identificado como o mais próximo e compara-se com o contorno de uma das faces que mais se assemelha a esta proporção (em preto).

Os desenhos estão sendo comparados com as estruturas mais recorrentes: paralela oblíqua (de acordo com as lógicas recomendadas pela norma brasileira de desenho técnico: com redução de $1 / 3$ para as fugitivas a $30^{\circ}$ graus, $1 / 2$ para as fugitivas de $45^{\circ}$ e $2 / 3$ para fugitivas a $60^{\circ}$ ); paralela ortogonal (isometria, dimetria e trimetria) ou sistema cônico (com 1(um), 2 (dois) ou 3 (três) pontos de fuga).

Os quadros 2 e 3 referem-se a dois casos já analisados. 
Quadro 2: análise dos desenhos - amostra 1.

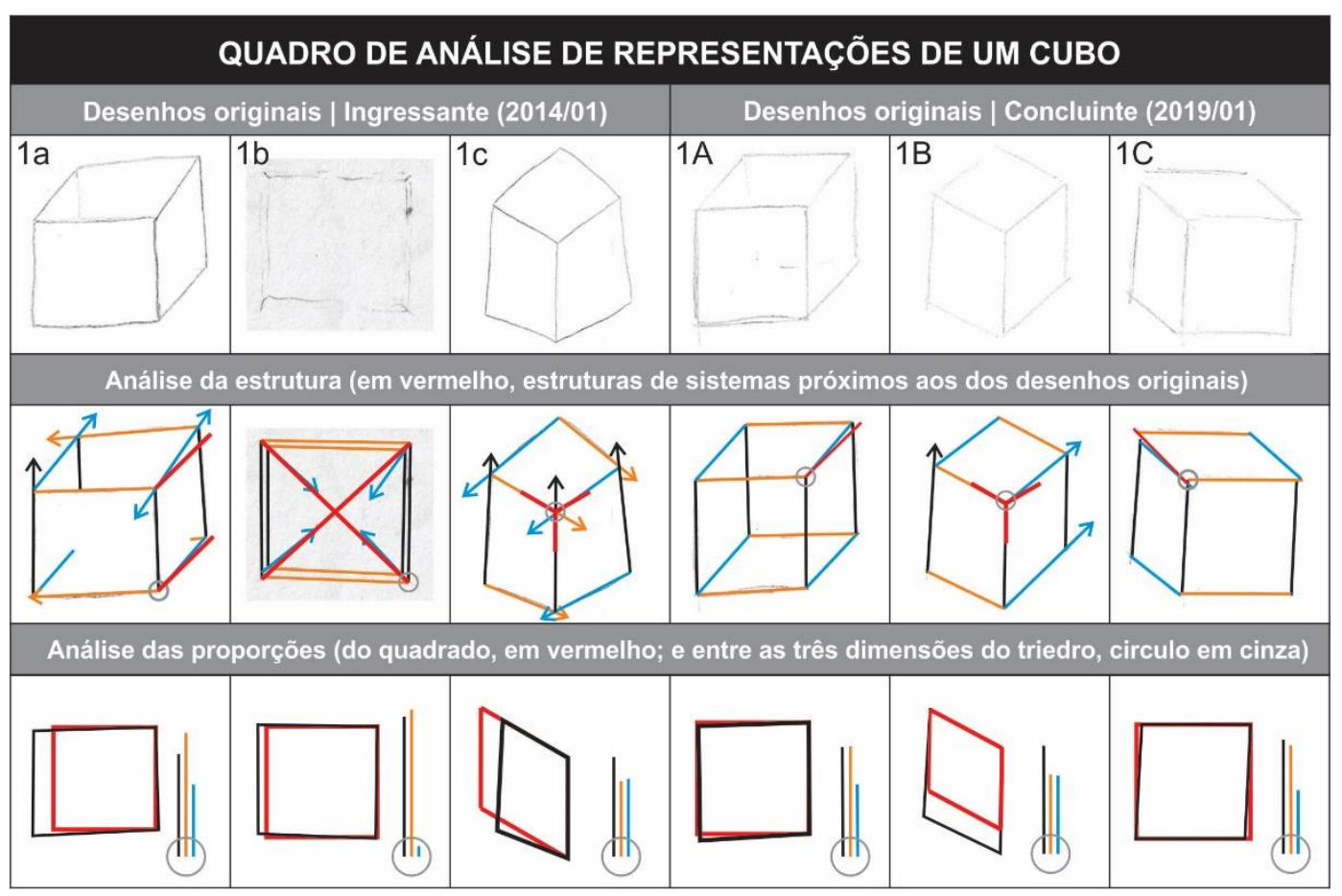

Fonte: Autoras.

Em relação às análises dos seis desenhos do caso 1 (Quadro 2), foram registradas as seguintes observações: 1) para o 1a, entende-se que a estrutura do desenho está coerente com as regras do sistema paralelo oblíquo para a representação de um cubo, com mínimos desvios admissíveis para o desenho à mão livre, inclusive, frente à indicação da norma brasileira de desenho, pois direciona as fugitivas a 45 graus com $1 / 2$ de redução da profundidade; 2) para o $1 \mathrm{~b}$ se observa a manutenção de paralelismos entre alturas e larguras, configurando o plano frontal da figura com proporção próxima a de um quadrado. As posições das arestas de profundidade sugerem um ponto de fuga, sendo que este não chega a se configurar como lugar geométrico de convergência das mesmas. A proporção entre os lados dificulta a compreensão de um cubo. 3) No 1c a estrutura está próxima de uma isometria, mas percebe-se também a tendência de delimitar convergências em sentido inverso (para largura e profundidade), o que remete à estrutura de uma perspectiva de três pontos de fuga. 0 fato de as alturas estarem proporcionalmente maiores às demais dimensões, compreende-se a figura diferente de um cubo. 4) o 1A indica que o estudante, nesta fase concluinte, aperfeiçoa a imagem produzida lá em seu ingresso, mantendo as regras do sistema paralelo oblíquo em relação aos paralelismos e representa as proporções exatas de um quadrado. A profundidade está com redução próxima à recomendada pela norma. 5) no $1 \mathrm{~B}$ se percebe a tomada de consciência em relação às regras de paralelismo do sistema adotado. Entretanto, não há o ajuste das dimensões de altura, em relação as demais dimensões, para facilitar a compreensão de um cubo (em isometria). 6) no 1C, o estudante demonstra a compreensão de operar no espaço no âmbito do sistema paralelo oblíquo (mudança de posição do observador). Observa-se o controle dos paralelismos, mas um descuido em delimitar os lugares geométricos dos vértices como origem de um triedro. A profundidade está com redução próxima à recomendada pela norma. 
Para este caso 1 observa-se também que o conjunto dos desenhos, no momento de ingresso, evoca uma carga figurativa, parecendo reproduzir imagens conhecidas, sem associação com a lógica das transformações no espaço projetivo. 0 desenho $1 \mathrm{a}$, está organizado pela repetição dos quadrados deslocados e as simetrias das arestas de profundidade (regra memorizada para a representação de um cubo/signo). 0 desenho 1b, apresenta a recursão do quadrado, com a união dos vértices correspondentes para simular a profundidade (sem a consciência de um ponto de fuga correspondente com a posição do observador). 0 desenho 1c traz a imagem do eixo isométrico, mas logo fica confuso por mesclar uma lógica do fenômeno visual/perceptivo que não tem a ver com a representação técnica e abstrata do sistema paralelo. Com isto, estes desenhos podem se situar mais no campo do espaço topológico do que no projetivo. Já no momento de conclusão, os três desenhos não incluem o sistema cônico. Isto não permite deduzir sobre a não apropriação deste conhecimento, mas pode indicar que pelo menos o sistema paralelo é um repertório mais imediato e confortável para este estudante, tendo em vista o limite de tempo para a realização do exercício. Devendo-se ter em conta que o sistema cônico exige um nível de abstração maior, em termos lógico-aritméticos. Estes desenhos demonstram a apropriação das regras de paralelismo, mas sem o controle de proporções em uma das representações.

Quadro 3: Análise dos desenhos - amostra 2.

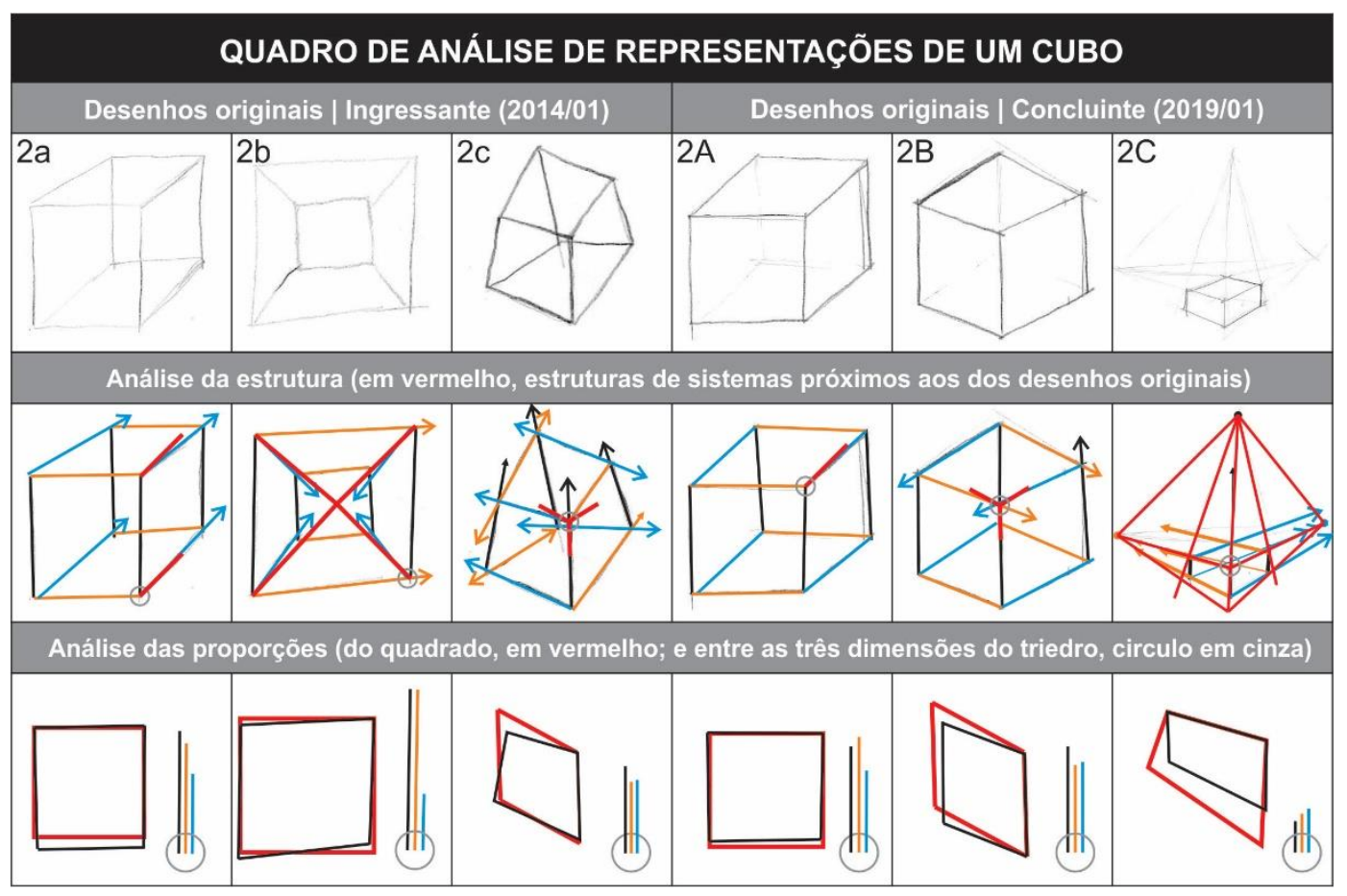

Fonte: Autoras.

Em relação às análises dos seis desenhos do caso 2 (Quadro 3), foram registradas as seguintes observações: 1) o 2a, observa-se a intenção de um desenho em perspectiva cônica, embora exista convergência, no máximo, de duas a duas das profundidades. Quanto à proporção observa-se a não correspondência de um quadrado e a relação da profundidade não condiz com as demais, não remetendo à compreensão de um cubo. 2) no $2 \mathrm{~b}$ a imagem remete a uma perspectiva cônica com um ponto de fuga, entretanto observa-se o quão figurativa se apresenta: sem configurar os lugares geométricos do 
ponto de fuga das profundidades e de um dos vértices como interseção de quatro arestas. 3) no 2c o sistema é dúbio. Por quebrar alguns paralelismos, fica próximo do cônico. Porém, o triedro frontal e a face superior indicam regras do paralelo oblíquo (uma dimetria) denunciando assim a falta de tomada de consciência do sistema adotado. 4) no 2A, uma imagem bastante similar ao 2a, o desenho é aperfeiçoado em relação aos paralelismos e às proporções (exatas de um quadrado), porém segue fugindo do padrão indicado pela norma para representar a profundidade. 5) no 2B a representação corresponde com uma isometria, considerando-se ser um desenho a mão. 6) o 2C, declara a técnica de três pontos de fuga, mas na hora de reforçar o traçado parece quase impor a regra de um sistema paralelo ortogonal, e a proporção adotada entre as arestas não remete à representação de um cubo.

A força da imagem, da evocação do figurativo, ilustrada pelo desenho $2 \mathrm{C}$, do caso 2, parece sobrepor à tentativa de um processo de apropriação do conhecimento (assimilação, acomodação e equilibração) para avançar do nível de abstração exigido pelo sistema paralelo para aquele exigido para a compreensão do sistema linear cônico. Observa-se que mesmo havendo a explicitação das regras do sistema cônico, com a localização de três pontos de fuga, a lógica da estrutura do cubo foi a de ter o paralelismo como invariante projetivo, incoerente com o sistema declarado. Fica claro que não houve a tomada de consciência por parte do estudante, podendo-se afirmar que ainda se encontra num momento de abstração empírica: sabe que deve representar os três pontos de fuga, tem esta imagem impregnada em sua memória, mas ainda não consegue retirar, ou seja, abstrair desta estrutura as qualidades necessárias à construção do cubo, o que se evidencia na análise da estrutura (segunda linha).

Desta maneira, em ambos os casos, 1 e 2, se identificam elementos que parecem denunciar a falta de tomada de consciência sobre o significado de cada representação, das transformações necessárias para a reversibilidade, para efetivamente facilitar a comunicação de um cubo. A teoria piagetiana nos permite compreender que, embora a cronologia seja variável, a possibilidade de maturidade para a representação ocorre em torno dos 11, 12 anos. Tendo-se em conta que os indivíduos envolvidos têm idade acima de 17 anos, entende-se que o sistema formativo não consegue aproveitar o tempo de cinco anos (mínimo do curso) para provocar a tomada de consciência sobre as habilidades necessárias para representar, tão imprescindíveis na formação para a ação projetual. É perceptível que o sistema educativo, de nível fundamental e médio, não dá conta de garantir um desenvolvimento de tais habilidades e, enquanto esta situação perdura, entende-se a necessidade de incentivar os estudantes ingressantes ao processo de reconhecimento de suas habilidades para representar. Nesta direção, investe-se na construção de discursos didáticos, impregnados de elementos de análise da teoria piagetiana como estratégia para auxiliar no processo de tomada de consciência, tanto por parte dos estudantes, sobre o conhecimento apropriado ao longo do processo, quanto por parte dos docentes, em relação ao tipo de abordagem mais adequada às necessidades desses mesmos estudantes.

Deve-se destacar que as análises dos desenhos das esferas e das árvores poderão melhor elucidar as questões aqui formuladas, sendo alvo das próximas etapas desta investigação.

\section{RESULTADOS E DISCUSSÃO}


Apoiando-se nas teorias piagetianas, este exercício docente buscou discutir e explicitar os parâmetros de análise para compreender os elementos indicativos de tomada de consciência das lógicas dos sistemas de projeção empregados em cada desenho analisado. Para isto, reuniu elementos relativos ao processo de constituição do próprio saber tratado, interpretando este processo histórico (dimensão genética) de sistematização da geometria euclidiana, projetiva e da topologia, no tempo, como um processo de equilibração das estruturas cognitivas. Uma rede de saberes que, apoiada em diferentes linguagens, desde a gráfica, a algébrica e a gráfico-algébrica, foi avançando em níveis de complexidade, desde abstrações empíricas aos processos de abstrações reflexionantes. A tomada de consciência sobre os invariantes projetivos unificou as geometrias clássicas, interpretando-se esta unificação como um ápice da abstração reflexionante. Estes invariantes são qualidades observadas dos sistemas de representação, exigindo assim dos estudantes estruturas cognitivas suficientes para estabelecer processos de abstração reflexionante.

Os resultados das análises dos desenhos, sem o propósito de categorizar o perfil dos participantes, contribuem para a formação docente na área de representação, construindo critérios e apontando estratégias para a configuração de discursos didáticos que possam auxiliar os estudantes, de maneira objetiva, a construírem capacidades cognitivas que são requisitadas ao longo de seus processos formativos no campo da arquitetura.

A exposição dos referenciais utilizados para a construção do método de análise e dos critérios utilizados, expressados de maneira gráfica, talvez possa auxiliar na tomada de consciência sobre o processo necessário a ser estabelecido pelo estudante. Como docentes, tem-se elementos que podem revelar eventuais deficiências na formação prévia dos estudantes que não proporcionaram o desenvolvimento das estruturas cognitivas relacionadas a compreensão das lógicas geométricas.

Parece que o sistema educativo de ensino fundamental e médio investe no desenvolvimento do raciocínio lógico-matemático, mas não investe suficientemente no desenvolvimento de um raciocínio geométrico-projetivo. Alguns sujeitos desenvolvem essas habilidades, provavelmente através de estímulos do meio em que vivem, como atividades lúdicas ou vivências diversas, enquanto outros acessam a universidade carentes em relação às noções do espaço e relações geométricas. Sendo assim, dadas estas carências no campo da geometria, talvez o tempo dedicado e os estímulos empregados para a desequilibração, junto ao processo formativo dessa especificidade, estejam aquém do necessário ao desenvolvimento de um novo patamar de equilibração das estruturas cognitivas desses estudantes. Por isso, deve-se oportunizar a reflexão para o autoconhecimento, no sentido de que essa tomada de consciência permita motivar e acelerar a assimilação, levando em consideração que, nesse processo, cada sujeito é um ser único, com características individuais e estímulos sociais muito particulares de acordo com o seu meio.

Como diagnóstico, a partir das avaliações da representação do cubo, tem-se que há repetição de estruturas previamente conhecidas sem a tomada de consciência dos significados de cada representação e/ou a habilidade para a representação do objeto em diferentes pontos de vista. Há um pequeno avanço no que diz respeito ao desenho quando alunos concluintes, mas ainda talvez pelo curto espaço de tempo de um curso de graduação ou por uma abordagem que considere que certas capacidades cognitivas já 
foram desenvolvidas, não é suficiente para que se diga que o aluno está em um patamar de abstração reflexionante.

\section{CONSIDERAÇÕES FINAIS}

Considera-se que o presente estudo contribui para o ensino de representação gráfica, assim como para a compreensão dos conceitos piagetianos em relação aos estádios de desenvolvimento cognitivo humano e o ensino das estruturas geométricas. Aponta-se como futuro da investigação a análise dos desenhos, já coletados, de uma esfera e uma árvore que buscarão elucidar e aprofundar alguns aspectos desenvolvidos a partir da análise do cubo.

\section{REFERÊNCIAS BIBLIOGRÁFICAS}

BORDA, Adriane A. S. Los saberes constitutivos del Modelado Geométrico y Visual, desde las instituciones científicas y profesionales a las escuelas de arquitectura. Un análises de Transposición Didáctica. Tese (doutorado). Universidad de Zaragoza, UNIZAR. Programa de Pós-graduação em Filosofía y Ciencias de la Educación. Zaragoza, Espanha, 2001.

BORDA, A.B.A.S; PIRES, J. F.; Vasconselos, T.; Nunes, C. Trajetórias de Aprendizagem em Representação Gráfica Digital. In: Revista Educação Gráfica, v. 16, p. 5-22, 2012.

CHING, Francis. Representação gráfica em Arquitetura. Tradução técnica: Alexandre Salvaterra - 5. ed. Porto Alegre: Bookman, 2011.

GIL, Antônio Carlos. Como elaborar projetos de pesquisa. São Paulo: Atlas, 2002.

GONCALVES, Marly de Menezes. A importância do conhecimento geométrico aliado ao uso dos meios digitais. In: Actas de Diseño: V Encuentro Latinoamericano de Diseño "Diseño en Palermo" Primer Congreso Latinoamericano de Enseñaza del Diseño. Buenos Aires: [s.n.]. 2011. p. 98-102.

GROAT, Linda. and WANG, David. Architectural Research Methods. 2th ed. Hoboken: John Wiley \& Sons, 2013.

KESSERLING, Thomas. Jean Piaget. Caxias do Sul, RS: Educs, 2008. 337 p.

KOPKE, Regina Coeli Moraes. M. Desenho e escola. In: I CONGRESSO INTERNACIONAL DE ENGENHARIA GRÁFICA NAS ARTES E NO DESENHO E XII SIMPÓSIO NACIONAL DE GEOMETRIA DESCRITIVA E DESENHO TÉCNICO. 1996, Florianópolis. Anais... Florianópolis: Editora da UFSM. 1996. p. 83-89.

KOPKE, Regina Coeli Moraes. Objetos esculpidos e a visão espacial. In: XIX SIMPÓSIO NACIONAL DE GEOMETRIA DESCRITIVA E DESENHO TÉCNICO E VIII INTERNACIONAL CONFERENCE ON GRAPHICS ENGINEERING FOR ARTS AND DESIGN. 2009, Bauru. Anais eletrônicos... Bauru: UNESP. 2009. p. 869-881. 
MONIZ, Carmen Machemer de Vasconcelos. Visualização espacial na perspectiva da epistemologia genética. Dissertação (mestrado). Universidade Federal do Rio Grande do Sul, Faculdade de Educação, Programa de Pós-Graduação em Educação. Porto Alegre, 2013.

MONTEnegro, Gildo. A Perspectiva dos Profissionais: Sombras, Insolação, Axonometria. São Paulo, Edgard Blucher, 1983.

PEREIRA, Danilo Candido; DUARTE, Maria Eduarda Rabelo; LOPES, Andiara Valentina de Freitas. Desenvolvendo a inteligência viso-espacial nos alunos de engenharia da UFPE. In: XX Simpósio Nacional De Geometria Descritiva e Desenho Técnico e IX Internacional Conference On Graphics Engineering for Arts and Design. 2011, Rio de Janeiro. Anais eletrônicos... Rio de Janeiro: UFRJ: Escola de Belas Artes. 2011.

PIAGET, Jean; INHELDER, Bärbel. A representação do espaço na criança. Porto Alegre: Artes Médicas, 1993.

PIAGET, Jean. Epistemologia genética. 3. ed. São Paulo, SP: Martins Fontes, 2007.

PIAGET, Jean. Abstração reflexionante: relações lógico-aritméticas e ordem das relações espaciais. Porto Alegre: Artes Médicas, 1995.

PIAGET, Jean. A equilibração das estruturas cognitivas: problema central do desenvolvimento. Rio de Janeiro: Zahar, 1976.

RODRIGUES, Maria Helena Wylie Lacerda. A visão espacial no contexto da "gráfica". In: I Congresso Internacional de Engenharia Gráfica nas Artes e no Desenho e XII Simpósio Nacional de Geometria Descritiva e Desenho Técnico. 1996, Florianópolis. Anais... Florianópolis: Editora da UFSM. 1996. p. 26-34.

SANZ, Ma Agripina; MORATALLA, Ascensión. 1998. Geometría y Arquitectura, Geometría en la Arquitectura. Cuadernos de apoyo a la docencia del Instituto Juan de Herrera de la Escuela de Arquitectura de Madrid.

SILVA JÚNIOR, Antônio Pedro. Desenho manual e modelagem geométrica: o desenvolvimento da lógica do espaço na representação gráfica. Dissertação (mestrado). Universidade Federal do Rio Grande do Sul, Faculdade de Educação, Programa de PósGraduação em Educação. Porto Alegre, 2007.

\section{AGRADECIMENTOS}

Agradecemos aos estudantes que colaboraram no desenvolvimento deste estudo, assim como as três instituições às quais estão vinculadas as pesquisadoras: Universidade Federal de Pelotas, Instituto Federal Sul-rio-grandense e Universidade de São Paulo. Agradecemos à CAPES pela bolsa de doutorado de uma das autoras envolvidas. 